\title{
THE PREPARATION AND USE OF 131I-TAGGED FIBRINOGEN TO DEMONSTRATE FIBRINOLYSIS
}

\author{
BY \\ W. ELSPETH CLEMENT AND GEORGE P. MCNICOL \\ From the Regional Physics Department, Glasgow, and the University Department of Medicine, \\ Royal Infirmary, Glasgow
}

(RECEIVED FOR PUBLICATION MAY 25, 1959)

The preparation of fibrinogen tagged with radioactive iodine $\left({ }^{131} \mathrm{I}\right)$ has been described in a preliminary communication (Clement and McNicol, 1958). The object of the present paper is to describe the chemical, electrophoretic, and chromatographic properties of the labelled protein, and to give an account of its use to demonstrate fibrinolytic activity in human plasma.

\section{Materials and Methods}

Preparation of Tagged Fibrinogen.-Radioactive iodine $\left({ }^{131} I_{2}\right)$ was prepared from $1 \mathrm{mc}$. carrier-free radioactive iodide (as sodium iodide) in $0.1 \mathrm{ml}$. dilute sodium thiosulphate solution by the addition of one drop of $\mathrm{N}^{127} \mathrm{I}_{2}$ in methanol and one drop of $0.01 \mathrm{~N}$ $\mathrm{H}_{2} \mathrm{SO}_{4}$. Then $5 \mathrm{ml}$. of human fibrinogen in citrate saline, concentration about $4 \mathrm{mg}$. per $\mathrm{ml}$., prepared by the Jaques phosphate-buffer method (Biggs and Macfarlane, 1957a), was added. The mixture was allowed to stand for five minutes at room temperature. It was then passed through a $\mathrm{Cl}$-phase resin column (" amberlite" IRA $400 \mathrm{Cl}$ ) to remove free iodide and iodine. The tagged fibrinogen was stored in small quantities at $-20^{\circ} \mathrm{C}$.

Electrophoresis.-Electrophoresis was carried out in a horizontal electrophoresis tank on Whatman No. 1 paper for 16 hours at 130 volts and 1 ma. for each $5 \mathrm{~cm}$. paper. Strips were stained for protein with bromophenol blue.

Chromatography.-This process was carried out by ascending chromatography in butanol acetic acid solvent. The strips were stained for amino-acids with diazotized sulphanilic acid and $10 \%$ potassium carbonate, and with $1 \%$ palladium chloride for iodide. Monoiodotyrosine, diiodotyrosine, and potassium iodide were run as markers.

Fibrin Estimation.-The method employed is a colorimetric one which consists in measuring the optical density on the addition of Folin Ciocalteau phenol reagent to an alkaline solution of fibrin (Holburn, 1951). The optical density of the colour developed is directly proportional to the concentration of tyrosine. This was measured by comparison with a standard tyrosine solution in a photoelectric spectro- photometer, the results being read off a calibration curve, and converted to milligrammes of fibrin by means of a conversion factor.

Thrombin.-Thrombin was prepared from expired bank blood by the method of Biggs and Macfarlane (1957b), and was stored at $-20^{\circ} \mathrm{C}$. Fresh samples were used for each experiment and were diluted with saline to give a clotting time of 10 seconds with an equal volume of plasma.

Buffer.-To $10 \mathrm{ml}$. of stock solution of sodium acetate/sodium barbitone $(9.714 \mathrm{~g}$. of $\mathrm{Na}$ acetate and $14.714 \mathrm{~g}$. $\mathrm{Na}$ barbitone made up to $500 \mathrm{ml}$. with distilled water) was added $10 \mathrm{ml}$. of $0.1 \mathrm{~N} \mathrm{HCl}$ and $30 \mathrm{ml}$. distilled water. Fresh buffer was made up for each experiment.

Glassware.-Glassware used in the production of the tagged fibrinogen was acid washed, alkali washed, thoroughly rinsed with distilled water, and dried in a hot air oven; the importance of clean glassware cannot be overemphasized. Other glassware was washed in a solution of "deosan" detergent, thoroughly rinsed, and dried overnight in a hot air oven at $100^{\circ} \mathrm{C}$. In some later experiments glassware was sterilized by heating to $160^{\circ} \mathrm{C}$. for one hour in a hot air oven.

Steps were taken at all stages to prevent bacterial contamination, and random cultures were sterile.

\section{Chemical Properties of Tagged Fibrinogen}

Efficient tagging depends on scrupulous cleanliness of glassware. If glassware is not clean, only about $70 \%$ of the total radioactivity may be in the clot formed by the addition of thrombin. The results to be described were all obtained with fibrinogen in which $88-94 \%$ of the radioactivity was coagulable.

As previously reported (Clement and McNicol, 1958 ), when $10 \%$ trichloracetic acid was added to precipitate the proteins, $98 \%$ of the activity was protein bound and came down with the precipitate.

Dilute sulphuric acid and $0.01 \mathrm{~N}$ potassium dichromate were added to the tagged fibrinogen to change any free iodide to iodine by an oxidation 


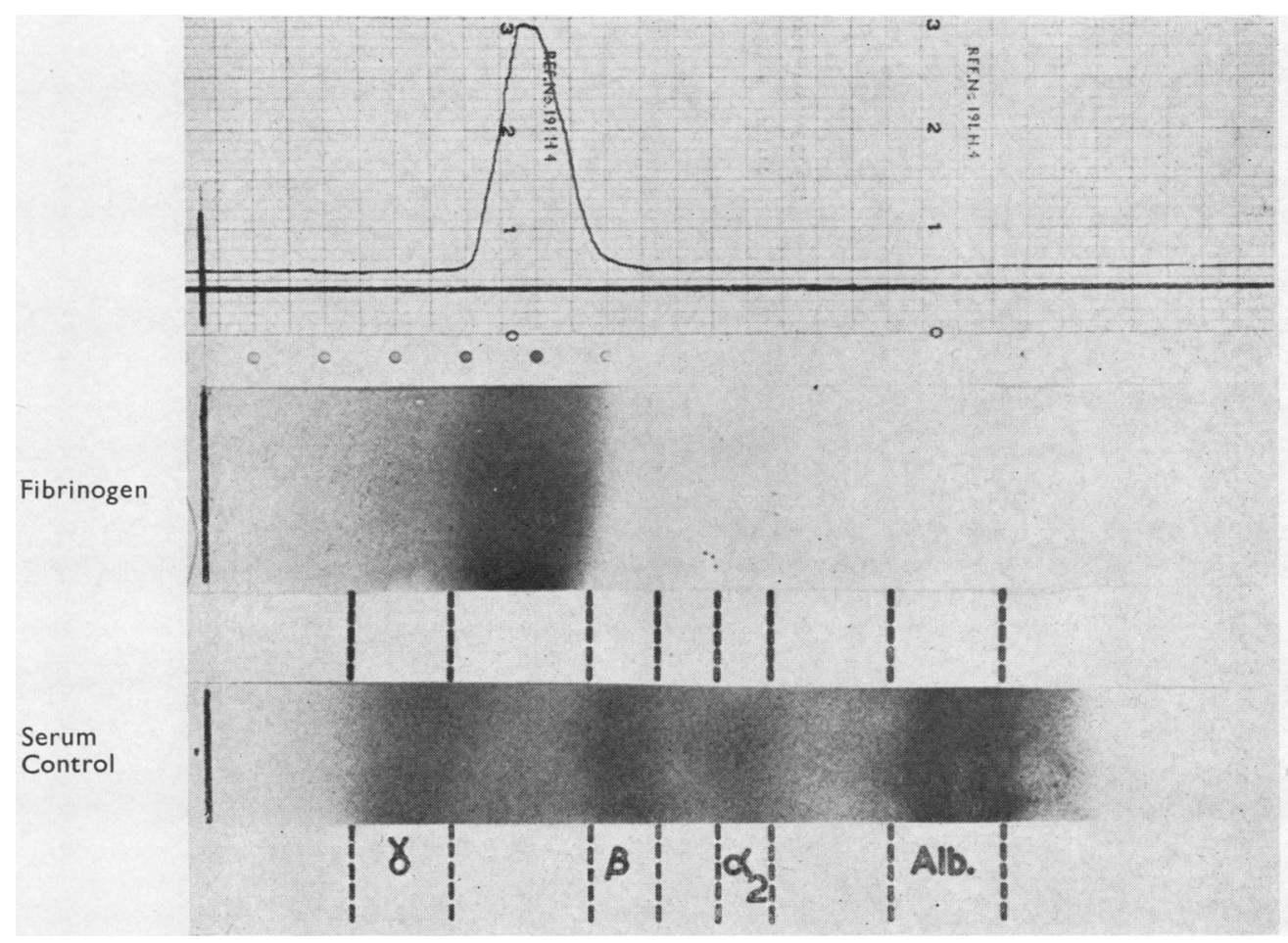

FIG. 1.-Electrophoresis of fibrinogen tagged with radioactive iodine. A control strip of normal serum run simultansously is shown below, and a recording of the radioactivity in the fibrinogen above the fibrinogen strip.

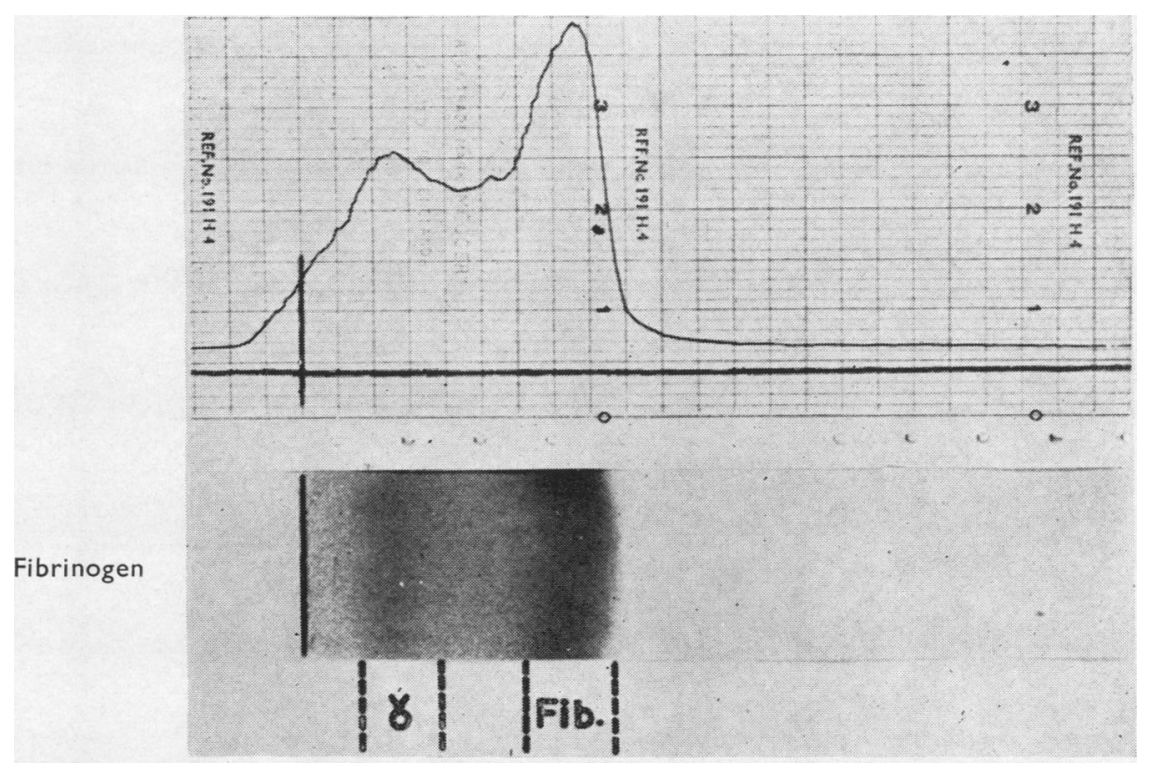

Fig. 2.-Electrophoresis strip of tagged fibrinogen contaminated with tagged $\gamma$ globulin. A recording of the radioactivity is shown above the electrophoresis strip 

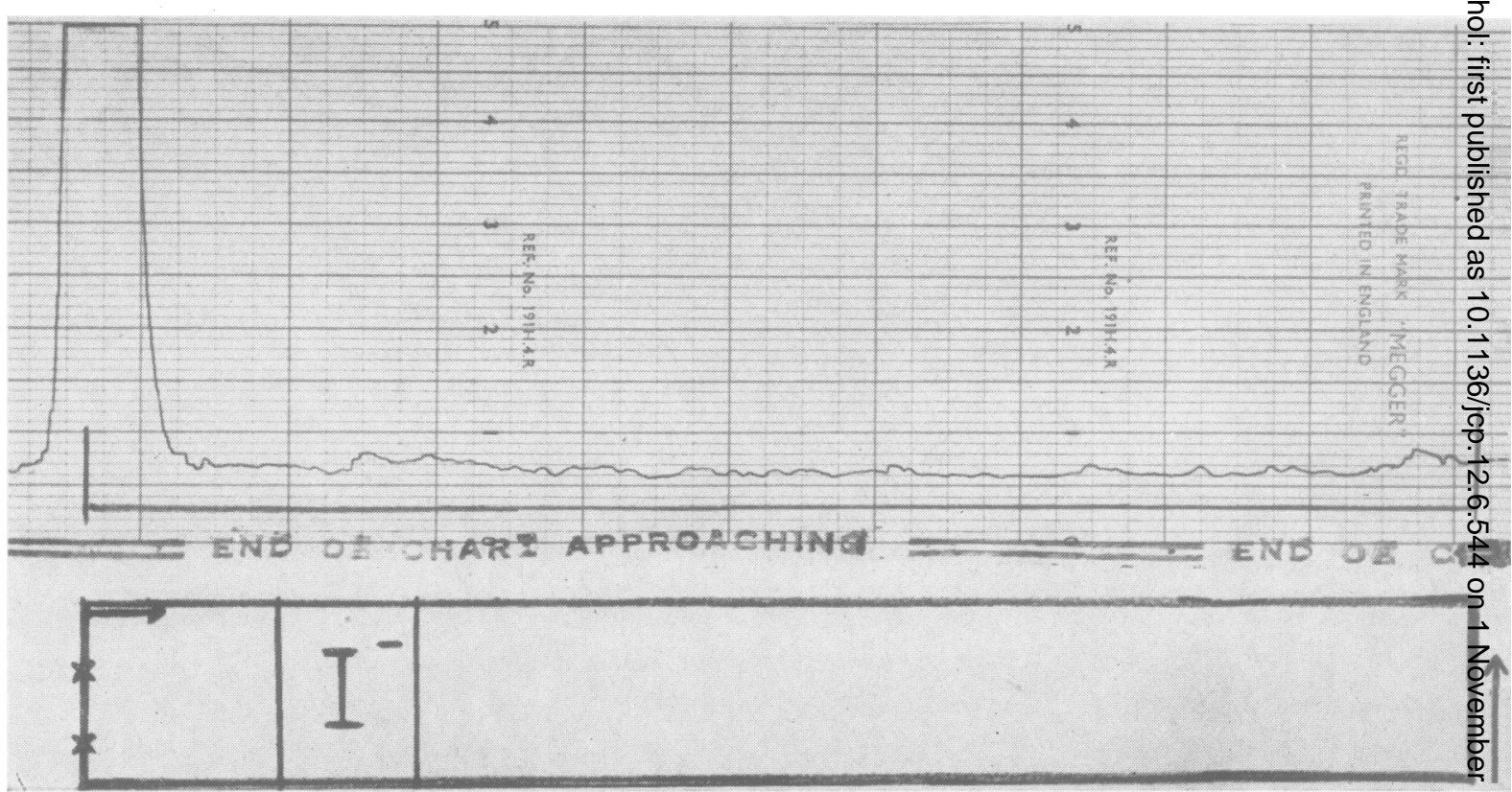

FIG. 3.-Chromatogram of tagged fibrinogen with recording of radioactivity above the chromatography strip.

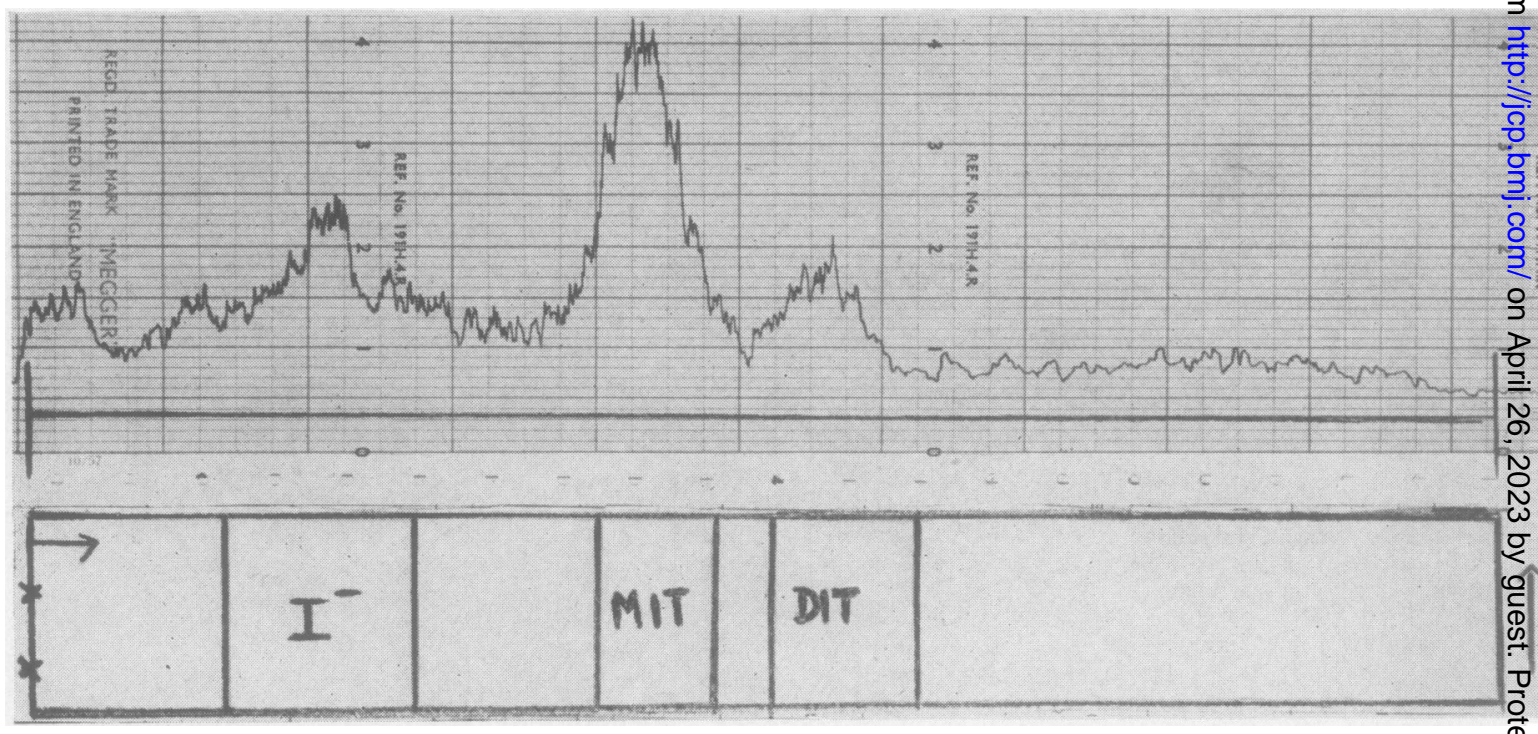

FIG. 4. Chromatogram of tagged fibrinogen after hydrolysis with trypsin. A recording of the radioactivity is shown above the chromatography stäip. 


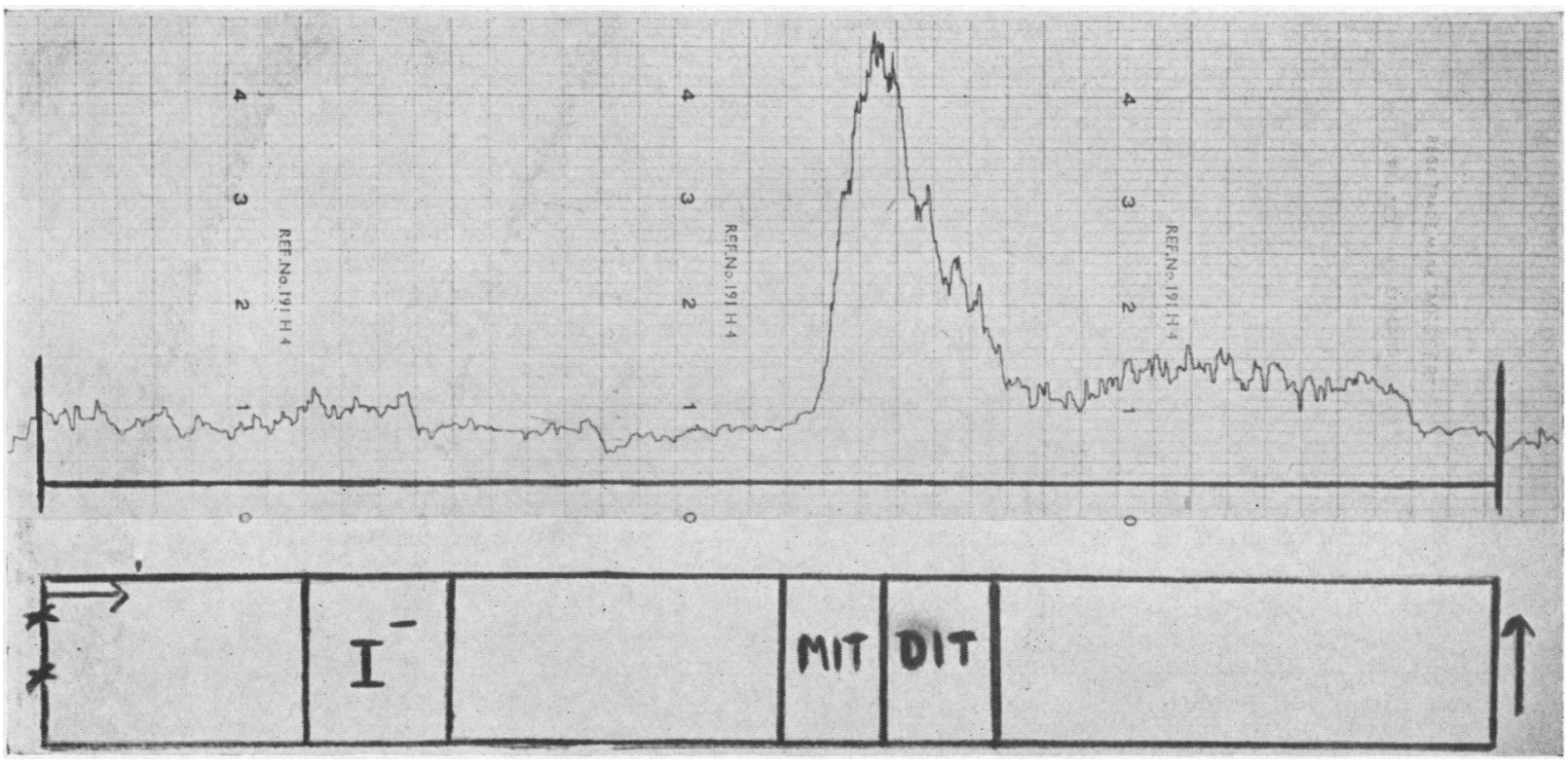

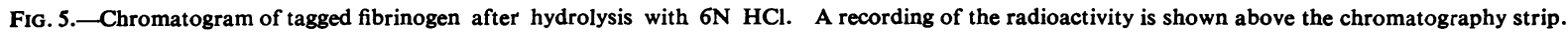

reaction. Chloroform extraction to remove free iodine was then carried out, and only $4 \%$ of the radioactivity was extractable.

\section{Electrophoresis and Chromatography of the Tagged Fibrinogen}

Fig. 1 shows an electrophoresis strip of the tagged fibrinogen with a control strip of normal serum run simultaneously. The strip was scanned for radioactivity by passing it between two GeigerMüller tubes linked through a ratemeter to a recording milliammeter. All the radioactivity is seen to be with the fibrinogen. Electrophoresis should be carried out with each batch of fibrinogen to exclude contamination with other proteins which would also tag. For instance, in Fig. 2 tagged globulin can be seen to be contaminating this particular batch of fibrinogen.

Fig. 3 shows a chromatogram of the tagged fibrinogen scanned for radioactivity which is all at the origin: no iodide was washed out. Chromatography was repeated after trypsin hydrolysis. Fig. 4 shows radioactivity, $63 \%$ of which is opposite mono- and di-iodotyrosine markers. Chromatography after hydrolysis with $6 \mathrm{~N} \mathrm{HCl}$ shows radioactivity which is opposite mono- and di-iodotyrosine markers (Fig. 5).

The electrophoresis strip demonstrates that the odination procedure described in our previous communication (Clement and McNicol, 1958) does in fact produce a protein, to which radioactive iodine is attached, with the electrophoretic mobility of fibrinogen. Chromatography of the untreated fibrinogen confirms that all the iodine is bound to the fibrinogen. Chromatography after trypsin hydrolysis suggests that much of the binding is as mono- and di-iodotyrosine. That tagging to tyrosines has not taken place after hydrolysis can be assumed from the result of chromatography after hydrolysis with $6 \mathrm{~N} \mathrm{HCl}$. It will be seen that most of the radioactivity is with mono- and di-iodotyrosine. The $p \mathrm{H}$ produced by $6 \mathrm{~N} \mathrm{HCl}$ is most unfavourable to tagging, which has almost certainly taken place before the $\mathrm{HCl}$ was added.

\section{Use of the Tagged Fibrinogen to Demonstrate Fibrinolytic Activity in Plasma}

Principle.-The tagged fibrinogen and plasma, in varying dilutions, were clotted with thrombin and incubated together for varying times. Fibrinolytic activity was measured by the reduced proportion of the total radioactivity which could be removed with the clots.

Technique.-Ten healthy subjects, aged between 20 and 40 years, were used. Blood was withdrawn by clean venepuncture at the same time of day, and was immediately mixed in an ice-cold container with 1 part of $3.8 \%$ sodium citrate B.P. to 9 parts of blood. Platelet-free plasma was obtained by high-speed centrifugation at $4^{\circ} \mathrm{C}$. To $20 \mathrm{ml}$. of the plasma $0.1 \mathrm{ml}$. of tagged fibrinogen was added and thoroughly 
TABLE I

QUANTITIES OF TEST PLASMA AND SALINE REQUIRED FOR INCREASING PLASMA DILUTIONS

\begin{tabular}{|c|c|c|c|c|c|c|}
\hline & \multicolumn{6}{|c|}{ Tube No. } \\
\hline & $\mathbf{I}$ & II & III & IV & $\mathbf{V}$ & VI \\
\hline $\begin{array}{l}\text { Plasma (ml.) } \ldots \\
\text { Saline ," } \\
\text { Thrombin , }, \ldots \\
\text { Plasma concen- }\end{array}$ & $\begin{array}{l}3 \\
1 \\
1\end{array}$ & $\begin{array}{l}2 \\
2 \\
1\end{array}$ & $\begin{array}{l}1 \\
3 \\
1\end{array}$ & $\begin{array}{l}0.5 \\
3.5 \\
1\end{array}$ & $\begin{array}{l}0.2 \\
3.8 \\
1\end{array}$ & $\begin{array}{l}0.1 \\
3.9 \\
1\end{array}$ \\
\hline tration $(\%)$ & 60 & 40 & 20 & 10 & 4 & 2 \\
\hline
\end{tabular}

mixed. The experiment was then set up as quickly as possible at $37^{\circ} \mathrm{C}$.

Table I shows the design of the experiment. For each subject, three sets of six test-tubes were set up, with progressive plasma, and therefore iodinated fibrinogen, dilutions. Each tube was clotted with
$1 \mathrm{ml}$. thrombin to give the final plasma dilutions shown. From the first set of six tubes the clots were removed immediately; the second and third sets of six tubes were incubated for four and 22 hours respectively, when the clots were removed. For all 18 tubes the radioactivity in the clots, and in the fluid from which they had been removed, was counted in a well-type scintillation counter.

For each subject the experiment was repeated on a subsequent day, collection of specimens and settingup of the experiment being carried out at $37^{\circ} \mathrm{C}$.

Results.-These are set out in Table II and Fig. 6. Using unincubated tubes as a base-line, percentage lysis was calculated from the increased proportion of the total radioactivity remaining in the fluid from which the clot had been removed. For example, if the percentage of the total radio-

TABLE II

PERCENTAGE LYSTS AFTER FOUR AND 22 HOURS' INCUBATION WITH "SETTING UP" AT $4^{\circ}$ C. AND $37^{\circ}$ C.*

\begin{tabular}{|c|c|c|c|c|c|c|c|}
\hline \multicolumn{2}{|c|}{ Plasma Concentration $(\%)$ : } & \multirow{2}{*}{ 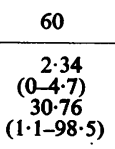 } & \multirow{2}{*}{ 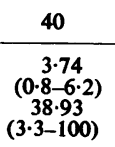 } & \multirow{2}{*}{$\frac{20}{\begin{array}{c}5 \cdot 65 \\
(1 \cdot 2-11 \cdot 9) \\
58 \cdot 24 \\
(10 \cdot 5-100)\end{array}}$} & \multirow{2}{*}{$\begin{array}{c}10 \\
\begin{array}{c}7 \cdot 06 \\
(1 \cdot 6-15 \cdot 7) \\
76 \cdot 37 \\
(43 \cdot 0-100)\end{array}\end{array}$} & \multirow{2}{*}{$\begin{array}{c}4 \\
\begin{array}{c}15 \cdot 3 \\
(6 \cdot 0-32 \cdot 8) \\
99 \cdot 55 \\
(97 \cdot 5-100)\end{array}\end{array}$} & \multirow{2}{*}{$\frac{2}{\begin{array}{c}50 \cdot 8 \\
(12 \cdot 2-100) \\
100\end{array}}$} \\
\hline $4^{\circ} \mathrm{C}$ & $\begin{array}{c}4 \mathrm{hr} . \\
\text { incubation } \\
22 \mathrm{hr} \text {. } \\
\text { incubation }\end{array}$ & & & & & & \\
\hline $37^{\circ} \mathrm{C}$. & $\begin{array}{c}4 \mathrm{hr} \text {. } \\
\text { incubation } \\
22 \mathrm{hr} \text {. } \\
\text { incubation }\end{array}$ & $\begin{array}{c}2.03 \\
(0-5 \cdot 7) \\
10 \cdot 43 \\
(0 \cdot 3-38 \cdot 8)\end{array}$ & $\begin{array}{c}2.67 \\
(0 \cdot 3-6 \cdot 4) \\
16.92 \\
(0.3-86.0)\end{array}$ & $\begin{array}{c}3.63 \\
(1 \cdot 4-7.0) \\
22 \cdot 81 \\
(2 \cdot 4-96 \cdot 5)\end{array}$ & $\begin{array}{c}4 \cdot 39 \\
(0 \cdot 9-9 \cdot 1) \\
30 \cdot 42 \\
(6 \cdot 6-100)\end{array}$ & $\begin{array}{c}7 \cdot 55 \\
(2 \cdot 2-15 \cdot 9) \\
65 \cdot 71 \\
(6 \cdot 7-100)\end{array}$ & $\begin{array}{c}19 \cdot 8 \\
(2 \cdot 1-68 \cdot 3) \\
85.72 \\
(18 \cdot 2-100)\end{array}$ \\
\hline
\end{tabular}

* Mean figures for the 10 subjects are shown, with ranges below in brackets.

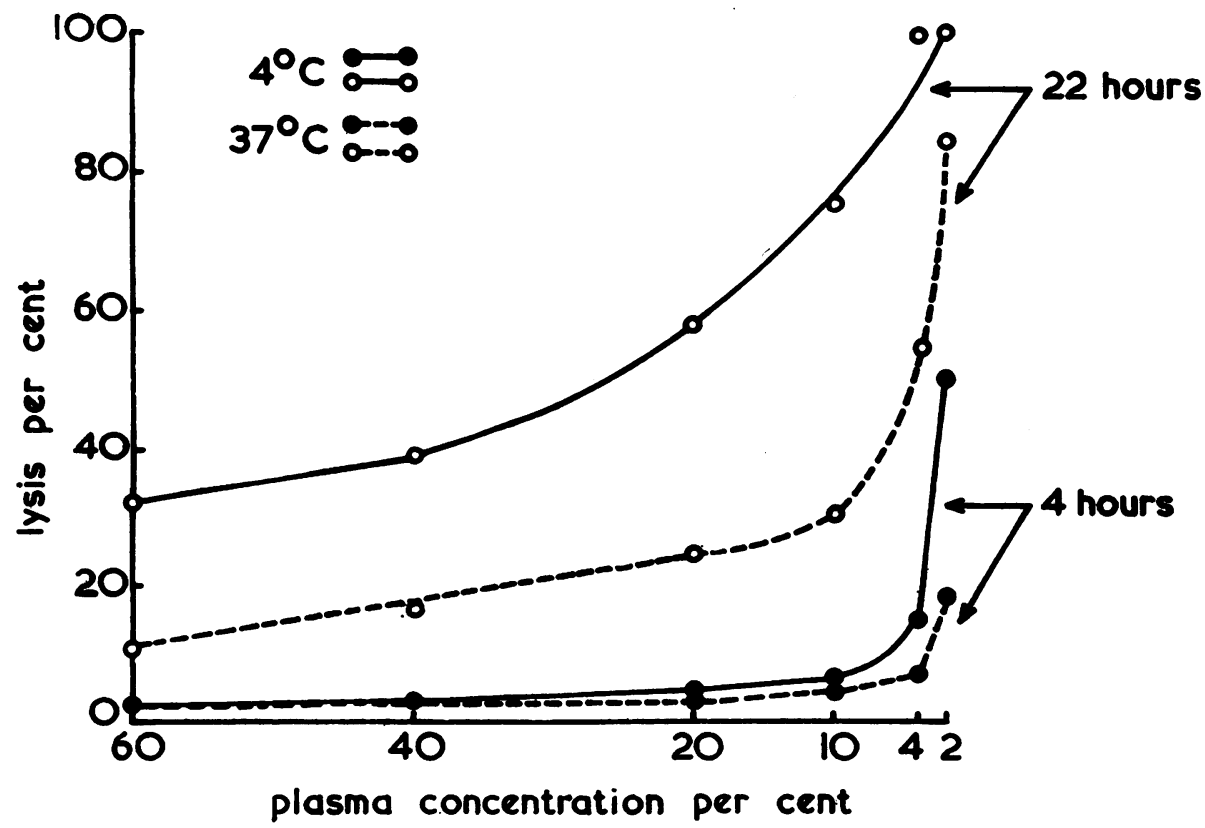

Fig. 6.-Mean figures for percentage lysis from 10 subjects, showing the effect of increasing time of incubation, increasing plasma dilutions, and the effect of temperature during setting up. 
TABLE III

MEASUREMENT OF FIBRINOLYTIC ACTIVITY USING TAGGED FIBRINOGEN COMPARED WITH A TYROSINE ESTIMATION*

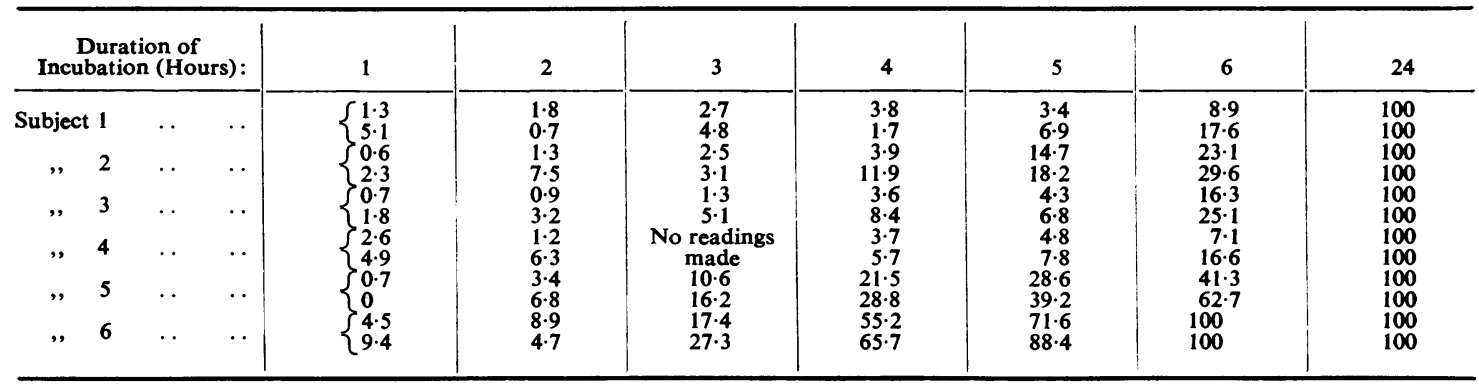

* The figures show fibrinolysis per cent. for six subjects for varying periods of incubation. The upper of each pair of results was obtained using tagged fibrinogen, the lower using the tyrosine estimation method.

activity left in the fluid after removal of the clot was before incubation $x \%$, and after incubation $y \%$, percentage lysis is calculated as $\frac{(y-x)}{100-x} \times 100$.

Mean figures, and ranges, for percentage lysis for the 10 subjects, for varying dilutions, incubation periods, and temperatures during setting up, are shown in Fig. 6 and Table II.

\section{Assessment of Fibrinolytic Activity with Tagged Fibrinogen Compared with a Tyrosine Estimation}

Technique.-Platelet-free plasma was obtained by the methods described above from six subjects, of whom four (subjects 1-4) were healthy young adult volunteers, and two (subjects 5 and 6) were patients with established cirrhosis of the liver.

The plasma from each patient was divided into two equal portions, to one of which was added $0.1 \mathrm{ml}$. of tagged fibrinogen. Two sets of eight test-tubes were prepared, each tube containing $2 \mathrm{ml}$. saline and $2 \mathrm{ml}$. buffer solution. To each of the first set of eight tubes was added $0.5 \mathrm{ml}$. plasma, and to each of the second set of eight tubes $0.5 \mathrm{ml}$. plasma with tagged fibrinogen. All 16 tubes were then clotted with $0.3 \mathrm{ml}$. thrombin. From one tube in each series the clot was removed after five minutes. The remaining 14 tubes were incubated at $37^{\circ} \mathrm{C}$. ; clots were removed from successive tubes in both series at hourly intervals for six hours, and at 24 hours.

For the radioactive series of tubes, the radioactivity in the clots, and in the fluid from which they had been removed, was measured and percentage lysis calculated.

The clots were removed from the non-radioactive tubes on glass rods. The clots were washed twice in normal saline, and the fibrin content of each clot was determined. Percentage lysis for each tube was calculated from the diminished content of fibrin present compared with that in the unincubated tube.

Results.-The results obtained with both methods for the six subjects are set out in Table III, and show that there is fair general agree- ment between the assessment of fibrinolytic activity using tagged fibrinogen and using a conventional method involving tyrosine estimation. The results with the tagged fibrinogen are on the whole somewhat lower than those obtained by the estimation of tyrosine ; however, the number of observations is too small to justify statistical analysis.

\section{Discussion}

The method of tagging fibrinogen with radioactive iodine which has been described in this paper is easily and quickly carried out. If scrupulously clean glassware is used about $90 \%$ of the radioactivity in most batches is in the clot produced by the addition of thrombin. This is a significant improvement on the method of Shulman and Tagnon (1950) in which only about $75 \%$ of the radioactivity was coagulable. Another relatively much more complex and lengthy method of tagging fibrinogen with radioactive iodine has also been described by Ambrus, Back, Mihalyi, and Ambrus (1956), who do not, however, state how much of the radioactivity in the final solution is coagulable.

Use of the Tagged Fibrinogen to Demonstrate Fibrinolysis.-The results obtained in these experiments are broadly similar to those obtained using a conventional technique by Fearnley and Lackner (1955). Lysis is much more marked after incubation for 22 hours than after incubation for four hours. Study of the figures shows that the differences between the results for the two periods of incubation are highly significant, despite the wide scatter of results in the two experiments. (In a $t$ test, for the most concentrated tubes, $\mathrm{P}<0.05$; for all others, $\mathrm{P}<0.01$.)

The results also confirm Fearnley and Lackner's observation that fibrinolytic activity is relatively much stronger in dilute solutions. 
It will be seen that fibrinolytic activity is greatly reduced in the experiments set up at $37^{\circ} \mathrm{C}$. compared with those set up at $4^{\circ} \mathrm{C}$.: the reduction in activity is highly significant after incubation for 22 hours (in a t test, for the most concentrated tubes, $\mathrm{P}<0.05$; for all other tubes, $\mathrm{P}<0.01$ ), but the reduction in activity is not statistically significant after only four hours' incubation. This evidence of the thermolability of the enzymes is in keeping with the findings of Fearnley and Tweed (1953).

It will be seen that in the two patients with cirrhosis of the liver fibrinolytic activity is more active than in the normal subjects: this finding is in keeping with the work of Kwaan, McFadzean, and Cook (1956).

The use of tagged fibrinogen to measure fibrinolytic activity should be of value in situations where other methods are unsuitable because of technical difficulties, for example, excessive turbidity preventing the use of the photospectrometer. Also, survival studies with tagged fibrinogen in vivo may offer a more physiological approach to certain problems of fibrinolysis.

\section{Summary}

A method of preparing fibrinogen tagged with radioactive iodine $\left({ }^{131} I\right)$ has been described. The chemical, electrophoretic, and chromatographic properties of the fibrinogen have been demon- strated. The tagged fibrinogen has been used to demonstrate fibrinolytic activity in human plasma, and to confirm that fibrinolysis is relatively more active in dilute solutions, and that fibrinolytic activity, studied in vitro in normal subjects, is thermolabile. The results obtained using tagged fibrinogen to measure fibrinolytic activity are similar to those obtained from a conventional method involving tyrosine estimation.

We thank Professor L. J. Davis, Dr. E. M. McGirr, and Dr. A. S. Douglas for their guidance in this work and the preparation of this paper, Dr. W. C. Watson, who carried out the electrophoresis, Miss K. Mair, who prepared the fibrinogen and thrombin, and Dr. A. I. Macdougall, who advised on certain aspects of the preparation of fibrinogen. We are also grateful to the Advisory Committee on Medical Research for Scotland, and to the Rankin Fund, for defraying part of the cost of the equipment, and to the Medical Research Council for technical assistance.

\section{REFERENCES}

Ambrus, J. L., Back, N., Mihalyi, E., and Ambrus, C. M. (1956). Circulation Res., 4, 430.

Biggs, R., and Macfarlane, R. G. (1957a). Human Blood Coagulation and its Disorders, 2nd ed., p. 389. Blackwell Scientific Publications, Oxford.

- (1957b). Ibid., p. 392.

Clement, W. E., and McNicol, G. P. (1958). Lancet, 2, 1212.

Fearnley, G. R., and Lackner, R. (1955). Brit. J. Haemat., 1, 189. - and Tweed, J. M. (1953). Clin. Sci., 12, 81.

Holburn, R. R. (1951). J. Lab. clin. Med., 37, 316.

Kwaan, H. C., McFadzean, A. J. S., and Cook, J. (1956). Lancet, 1, 132.

Shulman, N. R., and Tagnon, H. J. (1950). J. biol. Chem., 186, 69. 